\title{
Introducing Murine Microbiome Database (MMDB): A Curated Database with Taxonomic Profiling of the Healthy Mouse Gastrointestinal Microbiome
}

\author{
Junwon Yang ${ }^{1,2}$, Jonghyun Park ${ }^{1,2}$, Sein Park ${ }^{1,2}$, Inwoo Baek ${ }^{2,3}$ (D) and Jongsik Chun 1,2,3,* \\ 1 Interdisciplinary Program in Bioinformatics, Seoul National University, Seoul 08826, Korea; \\ yjunwon18@gmail.com (J.Y.); warwarsn@naver.com (J.P.); psi103706@gmail.com (S.P.) \\ 2 Institute of Molecular Biology \& Genetics, Seoul National University, Seoul 08826, Korea; \\ iwbaek0828@gmail.com \\ 3 School of Biological Sciences, Seoul National University, Seoul 08826, Korea \\ * Correspondence: jchun@snu.ac.kr
}

Received: 11 September 2019; Accepted: 21 October 2019; Published: 23 October 2019

\begin{abstract}
The gut microbiota modulates overall metabolism, the immune system and brain development of the host. The majority of mammalian gut microbiota consists of bacteria. Among various model animals, the mouse has been most widely used in pre-clinical biological experiments. The significant compositional differences in taxonomic profiles among different mouse strains due to gastrointestinal locations, genotypes and vendors have been well documented. However, details of such variations are yet to be elucidated. This study compiled and analyzed 16S rRNA gene-based taxonomic profiles of 554 healthy mouse samples from 14 different projects to construct a comprehensive database of the microbiome of a healthy mouse gastrointestinal tract. The database, named Murine Microbiome Database, should provide researchers with useful taxonomic information and better biological insight about how each taxon, such as genus and species, is associated with locations in the gastrointestinal tract, genotypes and vendors. The database is freely accessible over the Internet.
\end{abstract}

Keywords: database; metagenomics; mouse gut microbiome

\section{Introduction}

Mouse, Mus musculus, has long been used for biological studies as a mammalian model organism due to its low cost, short generation time and small size [1,2]. In particular, inbred laboratory mouse strains dominate genetic and immunological studies because each strain created by inbreeding over 20 generations is considered genetically identical [3]. The microbiome, also known as the second genome, is the complex community of microorganisms belonging to Archaea, Bacteria, Eukarya and viruses that can be found living both on and in vertebrates and have potential to affect host physiology, immunity and development [4-7]. Mice have been extensively used in microbiome-related studies which demonstrated a clear correlation between the mouse gut microbiome and host immune response [8-18]. For example, C57BL/6 mice obtained from the Jackson Laboratory and Taconic Biosciences showed substantially different resistances against the melanoma tumor, which resulted from the differences of their gut microbiota [19].

Although inbred laboratory mouse strains, including C57BL/6, have been widely used in biological experiments and pre-clinical testing, it is difficult for most researchers to comprehend the usual taxonomic make-up of mouse gut microbiota and the frequencies of each species or genus in different conditions, such as locations in the gastrointestinal (GI) tract, genotypes 
or vendors/environments [20-24]. Furthermore, there are no curated databases for the mouse gut microbiome.

In this study, we present the murine microbiome database (MMDB), which contains 16S rRNA gene-based microbiome taxonomic profiles (MTPs) of the healthy mouse gut microbiota with manually curated metadata. By compiling 554 microbiome samples, the overall compositional variations due to locations in the GI tract, genotypes and vendors were unraveled. Additionally, a variety of alpha-diversity indices were calculated to compare species richness and evenness of samples grouped by sampling locations, genotypes or vendors. Also, to assess overall relationships among the samples held in the database, the beta-diversity was calculated and compared using statistical values. Taken together, these results provide further insights into the relationship between the healthy mouse gut microbiome and the various conditions in terms of taxonomic compositions and species diversities within a specific condition or between the different conditions. Furthermore, the database with a web-based user-interface would provide easy access to these findings by the search services, which return the information of interest.

\section{Materials and Methods}

\subsection{Collection of Metagenome Sequences}

Amplicon data based on the bacterial $16 \mathrm{~S}$ rRNA gene were downloaded from the NCBI Short Read Archive (SRA) database with accompanying metadata. The publications associated with SRA data were manually checked and inserted into the MySQL database (https://www.mysql.com/). Only data labeled as the healthy mice with complete metadata and containing V4 or V3V4 region of 16S rRNA were compiled.

\subsection{Construction of Microbiome Taxonomic Profile (MTP) Database}

Each metagenome sequence was trimmed for V4 region by in-house code to use the same region for further analysis and analyzed using the EzBioCoud pipeline [25] with EzBioCoud 16S database version PKSSU4.0. In the pre-processing step, paired-end reads were merged in the case of paired-end sequencing, and primers used for polymerase chain reaction (PCR) amplification were trimmed by in-house code. Sequences with low quality were filtered out using the following criteria: (i) sequences with the lengths of $<100 \mathrm{bp}$ or $>2,000 \mathrm{bp}$, (ii) averaged $\mathrm{Q}$ value was $<25$, (iii) not predicted as a 16S rRNA gene by the hidden Markov model (HMM) based search or (iv) found to be a singleton when all sequences that did not match any of reference sequences with at least $97 \%$ similarity cutoff were clustered using the UCLUST program [26] with 97\% cutoff. Only non-redundant sequences were extracted and then subjected to the taxonomic assignment using the VSEARCH program [27] to search and calculate the similarity value of the query sequences against the EzBioCloud 16S database using the previously proposed cut-off values [28]. The sequences were checked for chimera using the UCHIME program [29] and operational taxonomic units (OTUs) were picked using the open-reference method [25]. Various alpha diversity indices (ACE, Chao1, Jackknife, Shannon, Simpson, NPShannon, Phylogenetic diversity) were calculated using OTU information. Only samples containing $>10,000$ valid reads were parsed and inserted into MySQL database after the processes.

The taxonomic composition of each microbiome sample at all taxonomic ranks was visualized using the Krona tool [30] in the web site. Chaol and Shannon indices were calculated with the rarefied number of reads $(10,175$ reads per sample) using the 'skbio' package in python (http: //scikit-bio.org/docs/0.2.0/generated/skbio.diversity.alpha.html) and visualized using the 'ggpubr' package in R [31]. Beta-diversity among the samples was computed with the rarefied number of counts (6266 counts per sample) and visualized by two-dimensional principal coordinates analysis (PCoA) plot of Bray-Curtis distances using the QIIME package [32]. 


\subsection{Statistics}

The Wilcoxon rank-sum test [33] was performed using the 'ggpubr' package in R to identify significant differences in the Chao1 and Shannon indices across different sampling locations, genotypes or vendors [31]. The analysis of similarity (ANOSIM) test was employed to see whether the groupings based on given variables for each factor were largely separate and statistically significant using the QIIME2 package [34].

\subsection{Operating System and Programming Languages}

The database and web site were constructed using MySQL, Spring Boot (https://spring.io/projects/ spring-boot) and JAVA under the Linux operating system.

\section{Results and Discussion}

\subsection{Taxonomic Profiles of Heathy Mouse Gastrointestinal Microbiome}

A total of 33,948,903 sequencing reads (554 samples from 14 projects) were processed and used to generate taxonomic profile data after filtering by quality and chimera-detection. More than 4700 species and 1700 genera were found in 554 mouse microbiome samples (Table 1). When microbiome samples were considered in 7 locations in the GI tract, interestingly, the most frequently found species were different in all areas (Table 2 and http://leb.snu.ac.kr/mmdb/frequency). The most frequently found bacterial species in feces was phylotype PAC001071_s, a tentative species that is represented by an uncultured sequence (nomenclature according to Yoon et al. [25]). This phylotype was found in $77.13 \%$ of samples with at least $1 \%$ relative abundance and belonged to the family Muribaculaceae, formerly known as the S24-7 group [35]. The members of this family were repeatedly reported as common inhabitants of the mouse gut microbiome [36-39]. In contrast, uncultured phylotype PAC001188_s belonging to the genus Oscillibacter was most frequently found in mouse cecum ( $66.67 \%$ of samples). In mouse duodenum, Akkermansia muciniphila that is considered one of the most important human intestinal bacteria, was second most frequently found.

Table 1. Summary statistics of the murine microbiome database (MMDB). OTU, operational taxonomic unit; SD, standard deviation.

\begin{tabular}{cc}
\hline & Counts \\
\hline Total numbers of projects & 14 \\
Total numbers of samples & 554 \\
Mean OTUs/sample \pm SD & $657 \pm 288$ \\
Mean valid reads/sample \pm SD & $61,280 \pm 27,893$ \\
Number of sampling locations in gastrointestinal (GI) tract & 7 \\
Number of strains/genotypes & 9 \\
Number of vendors & 10 \\
Total number of phyla found in all samples & 58 \\
Total number of classes found in all samples & 138 \\
Total number of orders found in all samples & 286 \\
Total number of families found in all samples & 585 \\
Total number of genera found in all samples & 1732 \\
Total number of species found in all samples & 4703 \\
\hline
\end{tabular}


Table 2. Top five most frequently found bacterial species in the gastrointestinal tract of healthy laboratory mice. Values were calculated by considering samples with at least $1 \%$ relative abundance.

\begin{tabular}{|c|c|c|c|c|c|}
\hline $\begin{array}{l}\text { Sampling } \\
\text { location }\end{array}$ & Name & Taxonomy & $\begin{array}{c}\text { Proportions } \\
\text { of samples } \\
(\%)\end{array}$ & $\begin{array}{c}\operatorname{Max} \\
(\%)\end{array}$ & $\begin{array}{l}\text { Median } \\
(\%)\end{array}$ \\
\hline Stomach & $\begin{array}{l}\text { Lactobacillus } \\
\text { gasseri group }\end{array}$ & $\begin{array}{l}\text { Firmicutes; Bacilli; Lactobacillales; } \\
\text { Lactobacillaceae; Lactobacillus; } \\
\text { Lactobacillus gasseri group; }\end{array}$ & 95.00 & 40.86 & 13.89 \\
\hline \multirow[t]{4}{*}{$(n=20)$} & $\begin{array}{l}\text { Lactobacillus } \\
\text { reuteri group }\end{array}$ & $\begin{array}{l}\text { Firmicutes; Bacilli; Lactobacillales; } \\
\text { Lactobacillaceae; Lactobacillus; } \\
\text { Lactobacillus reuteri group; }\end{array}$ & 95.00 & 55.55 & 11.64 \\
\hline & $\begin{array}{l}\text { Lactobacillus } \\
\text { intestinalis }\end{array}$ & $\begin{array}{c}\text { Firmicutes; Bacilli; Lactobacillales; } \\
\text { Lactobacillaceae; Lactobacillus; } \\
\text { Lactobacillus intestinalis; }\end{array}$ & 90.00 & 28.95 & 7.70 \\
\hline & PAC000185_s & $\begin{array}{c}\text { Bacteria; Proteobacteria; } \\
\text { Alphaproteobacteria; Rhodospirillales; } \\
\text { Rhodospirillaceae; LARJ_g; PAC000185_s; }\end{array}$ & 55.00 & 4.47 & 1.86 \\
\hline & PAC001472_s & $\begin{array}{c}\text { Bacteroidetes; Bacteroidia; Bacteroidales; } \\
\text { Muribaculaceae; PAC001472_g; } \\
\text { PAC001472_s; }\end{array}$ & 55.00 & 3.50 & 1.27 \\
\hline Dudenum & PAC001075_s & $\begin{array}{c}\text { Bacteroidetes; Bacteroidia; Bacteroidales; } \\
\text { Muribaculaceae; PAC000198_g; } \\
\text { PAC001075_s; }\end{array}$ & 93.75 & 6.30 & 2.07 \\
\hline \multirow[t]{4}{*}{$(n=16)$} & $\begin{array}{l}\text { Akkermansia } \\
\text { muciniphila }\end{array}$ & $\begin{array}{l}\text { Verrucomicrobia; Verrucomicrobiae; } \\
\text { Verrucomicrobiales; Akkermansiaceae; } \\
\text { Akkermansia; Akkermansia muciniphila; }\end{array}$ & 87.50 & 18.95 & 4.30 \\
\hline & $\begin{array}{l}\text { Lactobacillus } \\
\text { gasseri group }\end{array}$ & $\begin{array}{l}\text { Firmicutes; Bacilli; Lactobacillales; } \\
\text { Lactobacillaceae; Lactobacillus; } \\
\text { Lactobacillus gasseri group; }\end{array}$ & 81.25 & 36.58 & 5.20 \\
\hline & $\begin{array}{l}\text { PAC001065_s } \\
\text { group }\end{array}$ & $\begin{array}{c}\text { Bacteroidetes; Bacteroidia; Bacteroidales; } \\
\text { Muribaculaceae; PAC000186_g; } \\
\text { PAC001065_s group; }\end{array}$ & 81.25 & 7.48 & 4.06 \\
\hline & PAC001472_s & $\begin{array}{c}\text { Bacteroidetes; Bacteroidia; Bacteroidales; } \\
\text { Muribaculaceae; PAC001472_g; } \\
\text { PAC001472_s; }\end{array}$ & 81.25 & 9.17 & 3.75 \\
\hline Jejunum & $\begin{array}{l}\text { PAC001065_s } \\
\text { group }\end{array}$ & $\begin{array}{l}\text { Bacteroidetes; Bacteroidia; Bacteroidales; } \\
\text { Muribaculaceae; PAC000186_g; } \\
\text { PAC001065_s group; } \\
\text { Bacteroidetes; Bacteroidia; Bacteroidales; }\end{array}$ & 88.24 & 10.44 & 4.27 \\
\hline \multirow[t]{4}{*}{$(\mathrm{n}=34)$} & PAC001075_s & $\begin{array}{c}\text { Muribaculaceae; PAC000198_g; } \\
\text { PAC001075_s; }\end{array}$ & 88.24 & 11.83 & 3.12 \\
\hline & $\begin{array}{l}\text { Lactobacillus } \\
\text { gasseri group }\end{array}$ & $\begin{array}{l}\text { Firmicutes; Bacilli; Lactobacillales; } \\
\text { Lactobacillaceae; Lactobacillus; } \\
\text { Lactobacillus gasseri group; }\end{array}$ & 85.29 & 39.67 & 6.85 \\
\hline & $\begin{array}{l}\text { Lactobacillus } \\
\text { reuteri group }\end{array}$ & $\begin{array}{l}\text { Firmicutes; Bacilli; Lactobacillales; } \\
\text { Lactobacillaceae; Lactobacillus; } \\
\text { Lactobacillus reuteri group; }\end{array}$ & 82.35 & 31.43 & 3.04 \\
\hline & $\begin{array}{l}\text { Lactobacillus } \\
\text { intestinalis }\end{array}$ & $\begin{array}{l}\text { Firmicutes; Bacilli; Lactobacillales; } \\
\text { Lactobacillaceae; Lactobacillus; } \\
\text { Lactobacillus intestinalis; }\end{array}$ & 79.41 & 37.06 & 3.55 \\
\hline
\end{tabular}


Table 2. Cont.

\begin{tabular}{|c|c|c|c|c|c|}
\hline $\begin{array}{l}\text { Sampling } \\
\text { location }\end{array}$ & Name & Taxonomy & $\begin{array}{c}\text { Proportions } \\
\text { of samples } \\
(\%)\end{array}$ & $\begin{array}{c}\operatorname{Max} \\
(\%)\end{array}$ & $\begin{array}{l}\text { Median } \\
(\%)\end{array}$ \\
\hline Ileum & $\begin{array}{l}\text { Lactobacillus } \\
\text { gasseri group }\end{array}$ & $\begin{array}{l}\text { Firmicutes; Bacilli; Lactobacillales; } \\
\text { Lactobacillaceae; Lactobacillus; } \\
\text { Lactobacillus gasseri group; }\end{array}$ & 100.00 & 47.00 & 12.02 \\
\hline \multirow[t]{4}{*}{$(n=20)$} & $\begin{array}{l}\text { Lactobacillus } \\
\text { reuteri group }\end{array}$ & $\begin{array}{c}\text { Firmicutes; Bacilli; Lactobacillales; } \\
\text { Lactobacillaceae; Lactobacillus; } \\
\text { Lactobacillus reuteri group; }\end{array}$ & 95.00 & 39.17 & 5.93 \\
\hline & $\begin{array}{l}\text { Ileibacterium } \\
\text { valens }\end{array}$ & $\begin{array}{l}\text { Firmicutes; Erysipelotrichi; } \\
\text { Erysipelotrichales; Erysipelotrichaceae; } \\
\text { Ileibacterium; Ileibacterium valens; }\end{array}$ & 95.00 & 39.23 & 4.88 \\
\hline & PAC001472_s & $\begin{array}{c}\text { Bacteroidetes; Bacteroidia; Bacteroidales; } \\
\text { Muribaculaceae; PAC001472_g; } \\
\text { PAC001472_s; }\end{array}$ & 80.00 & 10.97 & 2.46 \\
\hline & $\begin{array}{l}\text { PAC001065_s } \\
\text { group }\end{array}$ & $\begin{array}{l}\text { Bacteroidetes; Bacteroidia; Bacteroidales; } \\
\text { Muribaculaceae; PAC000186_g; } \\
\text { PAC001065_s group; }\end{array}$ & 80.00 & 8.53 & 2.20 \\
\hline Cecum & PAC001188_s & $\begin{array}{c}\text { Firmicutes; Clostridia; Clostridiales; } \\
\text { Ruminococcaceae; Oscillibacter; } \\
\text { PAC001188_s; }\end{array}$ & 66.67 & 5.99 & 2.13 \\
\hline \multirow[t]{4}{*}{$(n=96)$} & KE159538_s & $\begin{array}{c}\text { Firmicutes; Clostridia; Clostridiales; } \\
\text { Lachnospiraceae; KE159538_g; } \\
\text { KE159538_s; }\end{array}$ & 45.83 & 20.38 & 4.38 \\
\hline & $\begin{array}{l}\text { KE159714_s } \\
\text { group }\end{array}$ & $\begin{array}{c}\text { Firmicutes; Clostridia; Clostridiales; } \\
\text { Ruminococcaceae; Oscillibacter; } \\
\text { KE159714_s group; }\end{array}$ & 41.67 & 16.71 & 2.03 \\
\hline & KE159628_s & $\begin{array}{l}\text { Bacteria; Firmicutes; Clostridia; } \\
\text { Clostridiales; Lachnospiraceae; } \\
\text { KE159628_g; KE159628_s; }\end{array}$ & 41.67 & 8.30 & 1.75 \\
\hline & PAC001080_s & $\begin{array}{c}\text { Tenericutes; Mollicutes; Acholeplasmatales; } \\
\text { Acholeplasmataceae; Acholeplasma_g2; } \\
\text { PAC001080_s; }\end{array}$ & 40.63 & 16.87 & 3.44 \\
\hline Colon & PAC001061_s & $\begin{array}{l}\text { Bacteroidetes; Bacteroidia; Bacteroidales; } \\
\text { Rikenellaceae; Alistipes; PAC001061_s; } \\
\text { Bacteroidetes; Bacteroidia; Bacteroidales; }\end{array}$ & 70.00 & 10.61 & 3.47 \\
\hline \multirow[t]{4}{*}{$(n=40)$} & PAC001074_s & $\begin{array}{c}\text { Muribaculaceae; PAC001074_g; } \\
\text { PAC001074_s; }\end{array}$ & 67.50 & 5.83 & 2.11 \\
\hline & PAC001471_s & $\begin{array}{l}\text { Bacteroidetes; Bacteroidia; Bacteroidales; } \\
\text { Rikenellaceae; Alistipes; PAC001471_s; }\end{array}$ & 52.50 & 12.00 & 5.04 \\
\hline & $\begin{array}{l}\text { Akkermansia } \\
\text { muciniphila }\end{array}$ & $\begin{array}{l}\text { Verrucomicrobia; Verrucomicrobiae; } \\
\text { Verrucomicrobiales; Akkermansiaceae; } \\
\text { Akkermansia: Akkermansia mucininhila. }\end{array}$ & 50.00 & 27.47 & 10.49 \\
\hline & PAC002478_s & $\begin{array}{c}\text { Bacteria; Proteobacteria; } \\
\text { Deltaproteobacteria; Desulfovibrionales; } \\
\text { Desulfovibrionaceae; LT706945_g; } \\
\text { PAC002478_s; }\end{array}$ & 50.00 & 42.00 & 10.27 \\
\hline \multirow{5}{*}{$(n=328)$} & PAC001071_s & $\begin{array}{c}\text { Bacteroidetes; Bacteroidia; Bacteroidales; } \\
\text { Muribaculaceae; PAC001068_g; } \\
\text { PAC001071_s; }\end{array}$ & 77.13 & 58.21 & 4.01 \\
\hline & PAC001060_s & $\begin{array}{l}\text { Bacteroidetes; Bacteroidia; Bacteroidales; } \\
\text { Rikenellaceae; Alistipes; PAC001060_s; }\end{array}$ & 55.79 & 52.82 & 6.78 \\
\hline & PAC001188_s & $\begin{array}{l}\text { Bacteria; Firmicutes; Clostridia; } \\
\text { Clostridiales; Ruminococcaceae; } \\
\text { Oscillibacter; PAC001188_s; }\end{array}$ & 49.70 & 18.59 & 2.18 \\
\hline & $\begin{array}{l}\text { PAC001369_s } \\
\text { group }\end{array}$ & $\begin{array}{c}\text { Bacteria; Firmicutes; Clostridia; } \\
\text { Clostridiales; Ruminococcaceae; } \\
\text { Oscillibacter; PAC001369_s group; }\end{array}$ & 39.63 & 12.95 & 1.99 \\
\hline & $\begin{array}{l}\text { PAC001065_s } \\
\text { group }\end{array}$ & $\begin{array}{c}\text { Bacteroidetes; Bacteroidia; Bacteroidales; } \\
\text { Muribaculaceae; PAC000186_g; } \\
\text { PAC001065_s group; }\end{array}$ & 37.50 & 13.89 & 2.23 \\
\hline
\end{tabular}


Additionally, a relative abundance of each taxon at different locations in the GI tract was also visualized as a series of boxplots, which provides users straight forward information about the distribution of each species or higher taxa. For example, the overall distribution of strains belonging to the Candidatus genus Arthromitus, previous known as segmented filamentous bacteria (SFB), along the GI tract of the healthy mice, is visualized in Figure 1a. The SFB has been extensively studied as an important modulator of mouse immunity [40] and is known to be present in a higher proportion in mice obtained from Taconic Farms than Jackson Laboratory [40], which was confirmed in our database (Figure 1b).

(a)

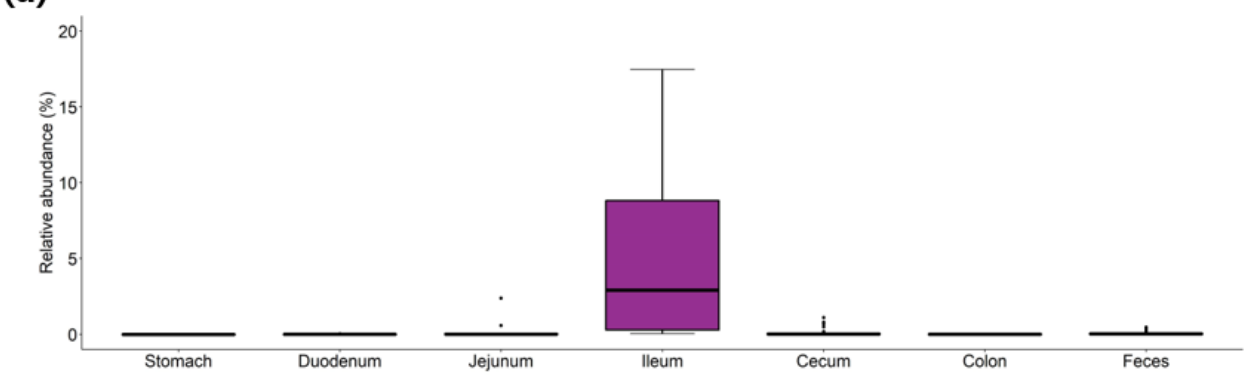

(b)

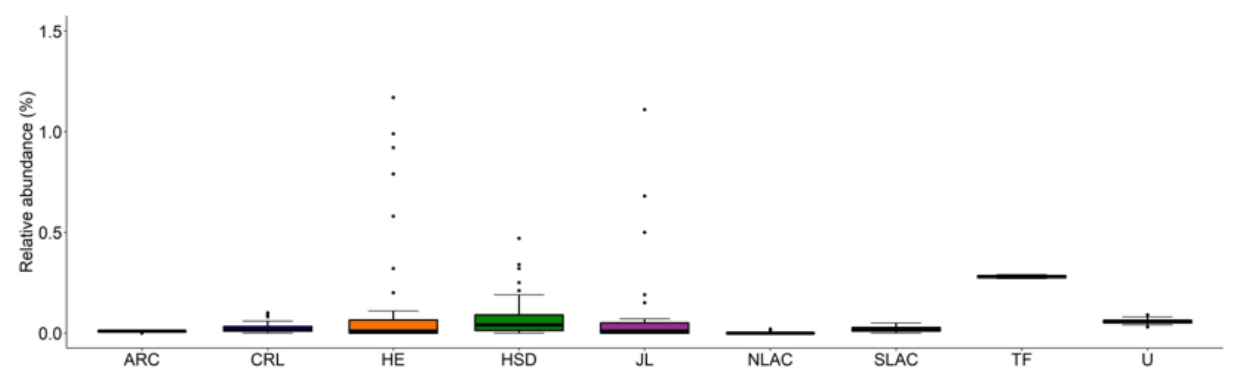

Figure 1. The relative abundance of the Candidatus genus Arthromitus (also known as segmented filamentous bacteria, SFB) (a) along the mouse gastrointestinal tract or (b) from different vendors. Data is accessible at http://leb.snu.ac.kr/mmdb/taxon/Arthromitus. ARC, Animal Resource Centre; CRL, Charles River Laboratories; HE, Harlan Envigo; HSD, Harlan Sprague Dawley; JL, Jackson Laboratory; NLAC, National Laboratory Animal Center; SLAC, Shanghai Laboratory Animal Center; TF, Taconic farms; U, UAMS.

\subsection{Alpha-Diversity Variations in the Healthy Mice}

A variety of alpha-diversity indices (ACE, Chao1, Jackknife, Shannon, Simpson, NPShannon, Phylogenetic diversity) were calculated and provided for each microbiome sample along with the rarefaction curve at the web site (e.g., see http://leb.snu.ac.kr/mmdb/sample/SRS347361 for a cecum sample of a PWK/PhJ mouse from Jackson Laboratory). The distributions of Chao1 and Shannon were further analyzed with the rarefied number of reads (10,175 reads per sample) in detail (Figure 2 and Table S1). As reported in multiple studies [41-44], species richness and evenness of microbiome samples from different GI locations, genotypes and vendors varied substantially. Species richness indicated by Chao1 is expected to be higher in the feces than ileum and jejunum [41], and species evenness indicated by Shannon is expected to be higher in the cecum, colon and feces than ileum and jejunum [44] which can be easily confirmed in Figure 2a and Table S1. 

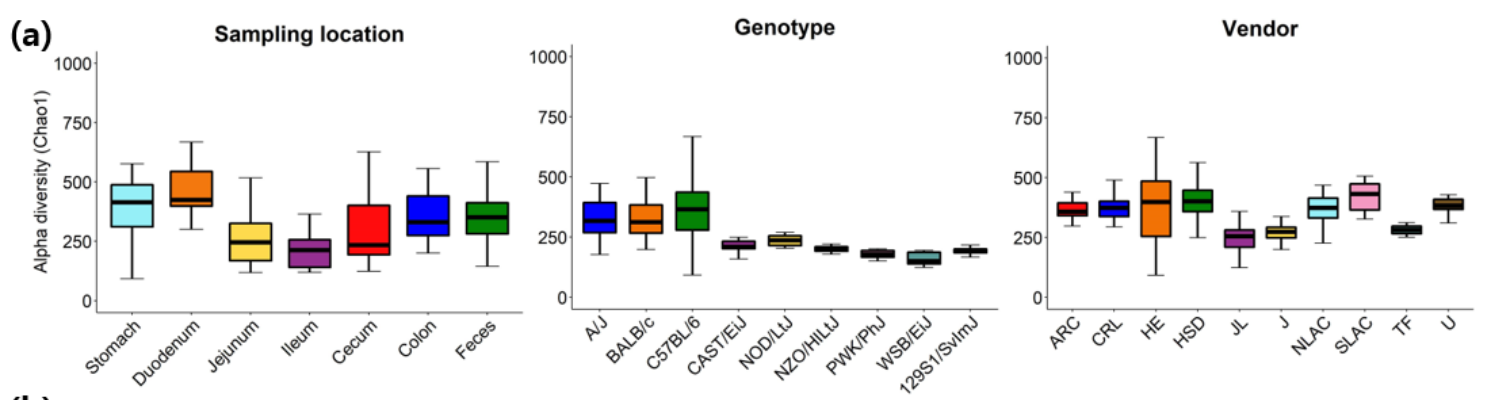

(b)

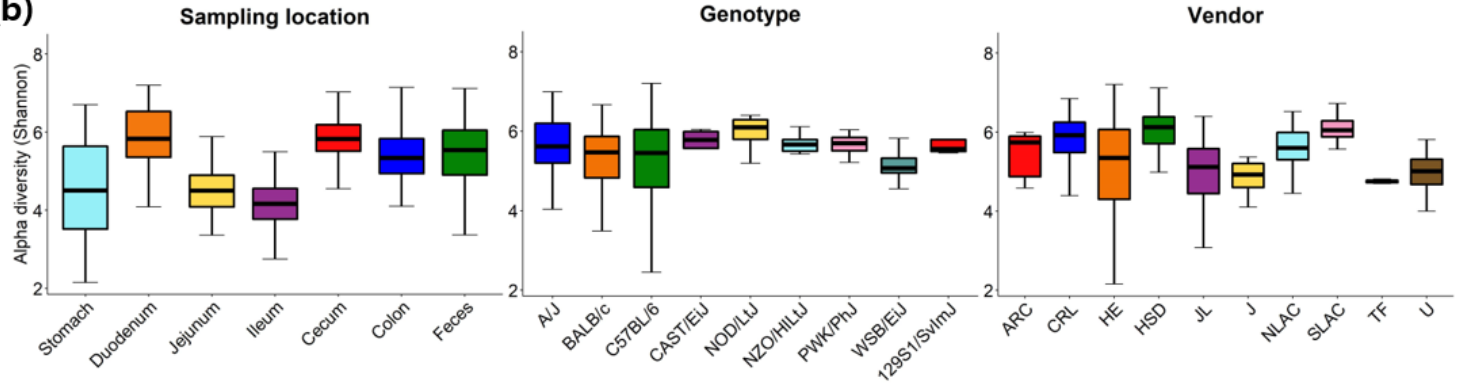

Figure 2. Alpha diversity of samples grouped by sampling locations, genotypes or vendors as measured using (a) Chao1 and (b) Shannon with the rarefied number of reads (10,175 reads per sample). ARC, Animal Resource Centre; CRL, Charles River Laboratories; HE, Harlan Envigo; HSD, Harlan Sprague Dawley; JL, Jackson Laboratory; J, Janvier; NLAC, National Laboratory Animal Center; SLAC, Shanghai Laboratory Animal Center; TF, Taconic farms; U, UAMS.

\subsection{Beta-Diversity}

To assess overall relationships among the samples held in the database, the beta-diversity was calculated with the rarefied number of counts (6,266 counts per sample) using Bray-Curtis distances and principal coordinates analysis (PCoA). Bacterial communities in the cecum, colon and feces samples are expected to cluster closely to one another [44], and it was also found in PCoA plot (Figure 3a) and ANOSIM pairwise comparisons (Table S2). The type of vendor (ANOSIM $R=0.666$ and $p=0.001$; Figure $3 \mathrm{~b}$ ) was a significant factor for the difference in taxonomic composition, whereas the genotype (ANOSIM $R=0.208$ and $p=0.001$; Figure $3 c$ ) was a less significant factor for the difference, which was similar result to Ericsson et al. [21]. 
(a)

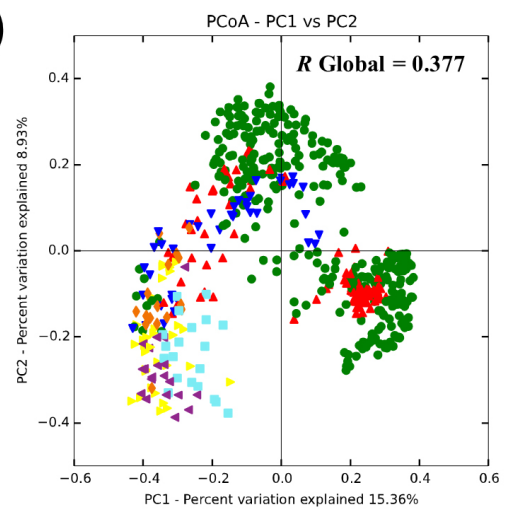

(b)

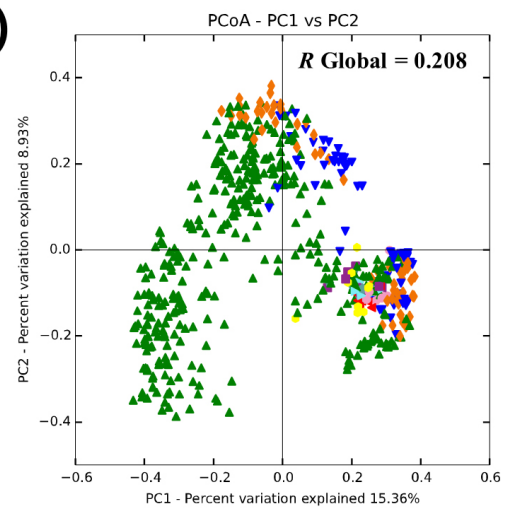

PCOA - PC1 vs PC2

(c)

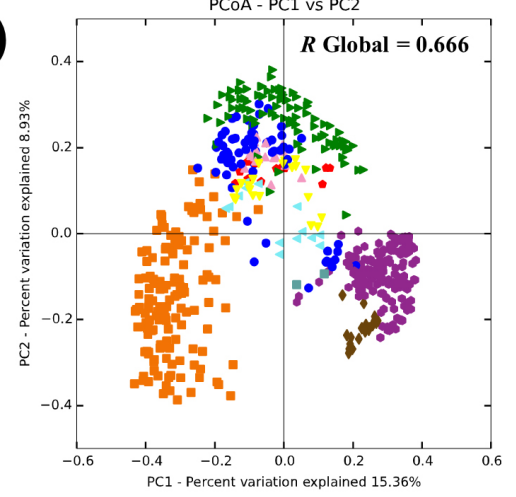



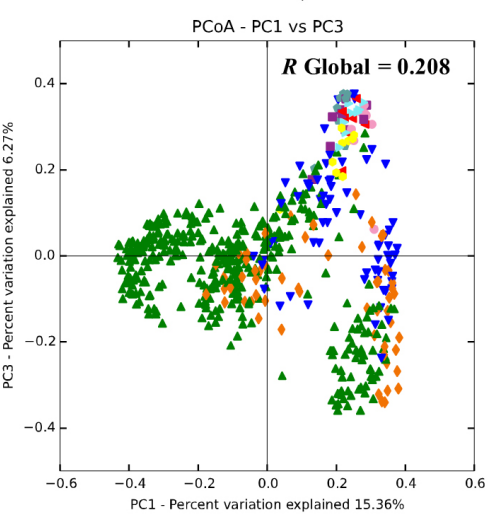

PCOA - PC1 vs PC3

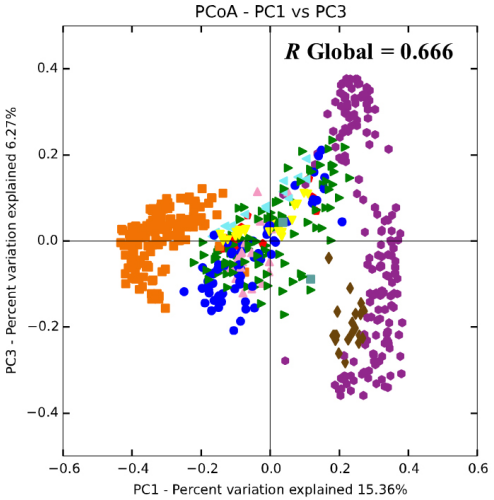

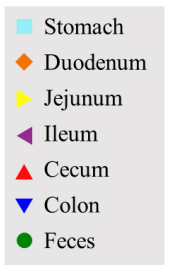

$\nabla \mathrm{A} / \mathrm{J}$

- BALB/c

A $\mathrm{C} 57 \mathrm{BL} / 6$

- CAST/EiJ

NOD/LtJ

NZO/HILtJ

$\mathrm{PWK} / \mathrm{PhJ}$

WSB/EiJ

$129 \mathrm{~S} 1 / \mathrm{SvImJ}$

Figure 3. Two-dimensional principal coordinates analysis plot of Bray-Curtis distances with the rarefied number of counts (6266 counts per sample) among the samples. Samples were grouped by (a) sampling locations, (b) genotypes or (c) vendors. Analysis of similarity (ANOSIM) $R$ value is indicated in the upper right of each graph ( $p=0.001$ with 999 permutations).

\section{Conclusions}

This study gathered taxonomic profiles of 554 gastrointestinal tract microbiome samples of healthy mice, then organized the data into an interactively browsable web-interface, named MMDB. As a result, a detail report on the taxonomic profile and alpha-diversity indices of each microbiome sample is provided. In addition, users of MMDB can easily find the distribution of each bacterial taxon, including $>4700$ species and $>1700$ genera, along with the locations in the GI tract or differences in genotypes or vendors, or combination of them. Taken together, it is fair to say that users of MMDB can easily access the information of healthy mouse gastrointestinal microbiome with curated metadata, and the information provided through MMDB should add valuable additional knowledge for researchers working on the microbiome and related diseases when they use laboratory mouse. The database can be publicly accessible at http://leb.snu.ac.kr/mmdb/. 
Supplementary Materials: The following are available online at http://www.mdpi.com/2076-2607/7/11/480/s1: Table S1: Wilcoxon rank-sum tests of differences in Chao1 index and Shannon index across different sampling locations, genotypes or vendors. Table S2: Pairwise ANOSIM results on the Bray-Curtis distance matrix across different sampling locations, genotypes or vendors with 999 permutations.

Author Contributions: Conceptualization, J.Y. and J.C.; methodology, J.Y. and J.C.; software, J.Y., S.P. and I.B.; formal analysis, J.Y.; investigation, J.Y. and J.P.; data curation, J.Y., J.P. and S.P.; writing-original draft preparation, J.Y.; writing-review and editing, I.B. and J.C.; visualization, J.Y.; supervision, J.C.; project administration, J.C.; funding acquisition, J.C.

Funding: This research was supported by the Korea Institute of Planning and Evaluation for Technology in Food, Agriculture, Forestry and Fisheries (IPET) funded by the Ministry of Agriculture, Food and Rural Affairs (MAFRA) of Korea, grant number 918013-04-2-SB010.

Conflicts of Interest: J.C. is a founder and CEO of ChunLab, Inc., provider of EzBioCloud 16S database. Other authors declare no conflict of interest. The funders had no role in the design of the study; in the collection, analyses, or interpretation of data; in the writing of the manuscript, or in the decision to publish the results.

\section{References}

1. Carter, A.M. Animal models of human placentation-a review. Placenta 2007, 28, S41-S47. [CrossRef] [PubMed]

2. $\quad$ Parker, K.D.; Albeke, S.E.; Gigley, J.P.; Goldstein, A.M.; Ward, N.L. Microbiome Composition in Both Wild-Type and Disease Model Mice Is Heavily Influenced by Mouse Facility. Front. Microbiol. 2018, 9, 1598. [CrossRef] [PubMed]

3. Beck, J.A.; Lloyd, S.; Hafezparast, M.; Lennon-Pierce, M.; Eppig, J.T.; Festing, M.F.; Fisher, E.M. Genealogies of mouse inbred strains. Nat. Genet. 2000, 24, 23-25. [CrossRef] [PubMed]

4. Bonder, M.J.; Kurilshikov, A.; Tigchelaar, E.F.; Mujagic, Z.; Imhann, F.; Vila, A.V.; Deelen, P.; Vatanen, T.; Schirmer, M.; Smeekens, S.P.; et al. The effect of host genetics on the gut microbiome. Nat. Genet. 2016, 48, 1407-1412. [CrossRef] [PubMed]

5. Colombo, B.M.; Scalvenzi, T.; Benlamara, S.; Pollet, N. Microbiota and mucosal immunity in amphibians. Front. Immunol. 2015, 6. [CrossRef] [PubMed]

6. Colston, T.J.; Jackson, C.R. Microbiome evolution along divergent branches of the vertebrate tree of life: What is known and unknown. Mol. Ecol. 2016, 25, 3776-3800. [CrossRef]

7. Fraune, S.; Bosch, T.C.G. Why bacteria matter in animal development and evolution. Bioessays 2010, 32, 571-580. [CrossRef]

8. $\quad$ Berer, K.; Mues, M.; Koutrolos, M.; Rasbi, Z.A.; Boziki, M.; Johner, C.; Wekerle, H.; Krishnamoorthy, G. Commensal microbiota and myelin autoantigen cooperate to trigger autoimmune demyelination. Nature 2011, 479, 538-541. [CrossRef]

9. Bohn, E.; Bechtold, O.; Zahir, N.; Frick, J.S.; Reimann, J.; Jilge, B.; Autenrieth, I.B. Host gene expression in the colon of gnotobiotic interleukin-2-deficient mice colonized with commensal colitogenic or noncolitogenic bacterial strains: common patterns and bacteria strain specific signatures. Inflamm. Bowel. Dis. 2006, 12, 853-862. [CrossRef]

10. Dianda, L.; Hanby, A.M.; Wright, N.A.; Sebesteny, A.; Hayday, A.C.; Owen, M.J. T cell receptor-alpha beta-deficient mice fail to develop colitis in the absence of a microbial environment. Am. J. Pathol. 1997, 150, 91-97.

11. Garrett, W.S.; Gallini, C.A.; Yatsunenko, T.; Michaud, M.; DuBois, A.; Delaney, M.L.; Punit, S.; Karlsson, M.; Bry, L.; Glickman, J.N.; et al. Enterobacteriaceae act in concert with the gut microbiota to induce spontaneous and maternally transmitted colitis. Cell Host Microbe. 2010, 8, 292-300. [CrossRef] [PubMed]

12. Lee, Y.K.; Menezes, J.S.; Umesaki, Y.; Mazmanian, S.K. Proinflammatory T-cell responses to gut microbiota promote experimental autoimmune encephalomyelitis. Proc. Natl. Acad. Sci. USA 2011, 108, 4615-4622. [CrossRef] [PubMed]

13. Rehakova, Z.; Capkova, J.; Stepankova, R.; Sinkora, J.; Louzecka, A.; Ivanyi, P.; Weinreich, S. Germ-free mice do not develop ankylosing enthesopathy, a spontaneous joint disease. Hum. Immunol. 2000, 61, 555-558. [CrossRef]

14. Rooks, M.G.; Garrett, W.S. Gut microbiota, metabolites and host immunity. Nat. Rev. Immunol. 2016, 16, 341-352. [CrossRef] [PubMed] 
15. Sellon, R.K.; Tonkonogy, S.; Schultz, M.; Dieleman, L.A.; Grenther, W.; Balish, E.; Rennick, D.M.; Sartor, R.B. Resident enteric bacteria are necessary for development of spontaneous colitis and immune system activation in interleukin-10-deficient mice. Infect. Immun. 1998, 66, 5224-5231. [PubMed]

16. Sudo, N.; Chida, Y.; Aiba, Y.; Sonoda, J.; Oyama, N.; Yu, X.N.; Kubo, C.; Koga, Y. Postnatal microbial colonization programs the hypothalamic-pituitary-adrenal system for stress response in mice. J. Physiol. 2004, 558, 263-275. [CrossRef] [PubMed]

17. Wen, L.; Ley, R.E.; Volchkov, P.Y.; Stranges, P.B.; Avanesyan, L.; Stonebraker, A.C.; Hu, C.; Wong, F.S.; Szot, G.L.; Bluestone, J.A.; et al. Innate immunity and intestinal microbiota in the development of Type 1 diabetes. Nature 2008, 455, 1109-1113. [CrossRef]

18. Wu, H.J.; Ivanov, I.I.; Darce, J.; Hattori, K.; Shima, T.; Umesaki, Y.; Littman, D.R.; Benoist, C.; Mathis, D. Gut-residing segmented filamentous bacteria drive autoimmune arthritis via T helper 17 cells. Immunity 2010, 32, 815-827. [CrossRef]

19. Sivan, A.; Corrales, L.; Hubert, N.; Williams, J.B.; Aquino-Michaels, K.; Earley, Z.M.; Benyamin, F.W.; Lei, Y.M.; Jabri, B.; Alegre, M.L.; et al. Commensal Bifidobacterium promotes antitumor immunity and facilitates anti-PD-L1 efficacy. Science 2015, 350, 1084-1089. [CrossRef]

20. Campbell, J.H.; Foster, C.M.; Vishnivetskaya, T.; Campbell, A.G.; Yang, Z.K.; Wymore, A.; Palumbo, A.V.; Chesler, E.J.; Podar, M. Host genetic and environmental effects on mouse intestinal microbiota. ISME J. 2012, 6, 2033-2044. [CrossRef]

21. Ericsson, A.C.; Davis, J.W.; Spollen, W.; Bivens, N.; Givan, S.; Hagan, C.E.; McIntosh, M.; Franklin, C.L. Effects of vendor and genetic background on the composition of the fecal microbiota of inbred mice. PLoS ONE 2015, 10, e0116704. [CrossRef] [PubMed]

22. Friswell, M.K.; Gika, H.; Stratford, I.J.; Theodoridis, G.; Telfer, B.; Wilson, I.D.; McBain, A.J. Site and strain-specific variation in gut microbiota profiles and metabolism in experimental mice. PLOS ONE 2010, 5, e8584. [CrossRef] [PubMed]

23. Hufeldt, M.R.; Nielsen, D.S.; Vogensen, F.K.; Midtvedt, T.; Hansen, A.K. Variation in the gut microbiota of laboratory mice is related to both genetic and environmental factors. Comp. Med. 2010, 60, 336-347. [PubMed]

24. Zmora, N.; Zilberman-Schapira, G.; Suez, J.; Mor, U.; Dori-Bachash, M.; Bashiardes, S.; Kotler, E.; Zur, M.; Regev-Lehavi, D.; Brik, R.B.; et al. Personalized Gut Mucosal Colonization Resistance to Empiric Probiotics Is Associated with Unique Host and Microbiome Features. Cell 2018, 174, 1388-1405. [CrossRef]

25. Yoon, S.H.; Ha, S.M.; Kwon, S.; Lim, J.; Kim, Y.; Seo, H.; Chun, J. Introducing EzBioCloud: a taxonomically united database of $16 \mathrm{~S}$ rRNA gene sequences and whole-genome assemblies. Int. J. Syst. Evol. Microbiol. 2017, 67, 1613-1617. [CrossRef]

26. Edgar, R.C. Search and clustering orders of magnitude faster than BLAST. Bioinformatics 2010, 26, $2460-2461$. [CrossRef]

27. Rognes, T.; Flouri, T.; Nichols, B.; Quince, C.; Mahe, F. VSEARCH: a versatile open source tool for metagenomics. Peer J. 2016, 4, e2584. [CrossRef]

28. Yarza, P.; Yilmaz, P.; Pruesse, E.; Glockner, F.O.; Ludwig, W.; Schleifer, K.H.; Whitman, W.B.; Euzeby, J.; Amann, R.; Rossello-Mora, R. Uniting the classification of cultured and uncultured bacteria and archaea using $16 \mathrm{~S}$ rRNA gene sequences. Nat. Rev. Microbiol. 2014, 12, 635-645. [CrossRef]

29. Edgar, R.C.; Haas, B.J.; Clemente, J.C.; Quince, C.; Knight, R. UCHIME improves sensitivity and speed of chimera detection. Bioinformatics 2011, 27, 2194-2200. [CrossRef]

30. Ondov, B.D.; Bergman, N.H.; Phillippy, A.M. Interactive metagenomic visualization in a Web browser. BMC Bioinform. 2011, 12, 385. [CrossRef]

31. Kassambara, A. ggpubr:"ggplot2" based publication ready plots. R package version $0.12017,6$.

32. Caporaso, J.G.; Kuczynski, J.; Stombaugh, J.; Bittinger, K.; Bushman, F.D.; Costello, E.K.; Fierer, N.; Pena, A.G.; Goodrich, J.K.; Gordon, J.I.; et al. QIIME allows analysis of high-throughput community sequencing data. Nat. Methods 2010, 7, 335-336. [CrossRef] [PubMed]

33. Wilcoxon, F.; Katti, S.; Wilcox, R.A. Critical values and probability levels for the Wilcoxon rank sum test and the Wilcoxon signed rank test. In Selected Tables in Mathematical Statistics; Harter, H., Owen, D.B., Eds.; Markham Publishing Company: Markham, ON, Canada, 1970; Volume 1, pp. 171-259. 
34. Bolyen, E.; Rideout, J.R.; Dillon, M.R.; Bokulich, N.A.; Abnet, C.C.; Al-Ghalith, G.A.; Alexander, H.; Alm, E.J.; Arumugam, M.; Asnicar, F.; et al. Reproducible, interactive, scalable and extensible microbiome data science using QIIME 2. Nat. Biotechnol. 2019, 37, 852-857. [CrossRef] [PubMed]

35. Lagkouvardos, I.; Lesker, T.R.; Hitch, T.C.A.; Galvez, E.J.C.; Smit, N.; Neuhaus, K.; Wang, J.; Baines, J.F.; Abt, B.; Stecher, B.; et al. Sequence and cultivation study of Muribaculaceae reveals novel species, host preference, and functional potential of this yet undescribed family. Microbiome. 2019, 7, 28. [CrossRef]

36. Wang, L.; Chen, C.; Cui, S.; Lee, Y.K.; Wang, G.; Zhao, J.; Zhang, H.; Chen, W. Adhesive Bifidobacterium Induced Changes in Cecal Microbiome Alleviated Constipation in Mice. Front. Microbiol. 2019, $10,1721$. [CrossRef]

37. Moreira Junior, R.E.; de Carvalho, L.M.; Pedersen, A.S.B.; Damasceno, S.; Maioli, T.U.; de Faria, A.M.C.; Godard, A.L.B. Interaction between high-fat diet and ethanol intake leads to changes on the fecal microbiome. J. Nutr. Biochem. 2019, 72, 108215. [CrossRef]

38. Guo, B.; Yang, B.; Pang, X.; Chen, T.; Chen, F.; Cheng, K.W. Fucoxanthin modulates cecal and fecal microbiota differently based on diet. Food Funct. 2019. [CrossRef]

39. Fan, J.; Wang, Y.; You, Y.; Ai, Z.; Dai, W.; Piao, C.; Liu, J.; Wang, Y. Fermented ginseng improved alcohol liver injury in association with changes in the gut microbiota of mice. Food Funct. 2019. [CrossRef]

40. Ivanov, I.I.; Atarashi, K.; Manel, N.; Brodie, E.L.; Shima, T.; Karaoz, U.; Wei, D.; Goldfarb, K.C.; Santee, C.A.; Lynch, S.V.; et al. Induction of intestinal Th17 cells by segmented filamentous bacteria. Cell 2009, 139, 485-498. [CrossRef]

41. Bluemel, S.; Wang, L.; Kuelbs, C.; Moncera, K.; Torralba, M.; Singh, H.; Fouts, D.E.; Schnabl, B. Intestinal and hepatic microbiota changes associated with chronic ethanol administration in mice. Gut Microbes. 2019, 14, 1-11. [CrossRef]

42. Allen, J.M.; Berg Miller, M.E.; Pence, B.D.; Whitlock, K.; Nehra, V.; Gaskins, H.R.; White, B.A.; Fryer, J.D.; Woods, J.A. Voluntary and forced exercise differentially alters the gut microbiome in C57BL/6J mice. J. Appl. Physiol. (1985) 2015, 118, 1059-1066. [CrossRef] [PubMed]

43. Fransen, F.; Zagato, E.; Mazzini, E.; Fosso, B.; Manzari, C.; El Aidy, S.; Chiavelli, A.; D’Erchia, A.M.; Sethi, M.K.; Pabst, O.; et al. BALB/c and C57BL/6 Mice Differ in Polyreactive IgA Abundance, which Impacts the Generation of Antigen-Specific IgA and Microbiota Diversity. Immunity 2015, 43, 527-540. [CrossRef] [PubMed]

44. Gu, S.; Chen, D.; Zhang, J.N.; Lv, X.; Wang, K.; Duan, L.P.; Nie, Y.; Wu, X.L. Bacterial community mapping of the mouse gastrointestinal tract. PLoS ONE 2013, 8, e74957. [CrossRef] [PubMed] 